\title{
Process Fairness and Dynamic Consistency
}

\author{
Stefan T. Trautmann \\ TIBER, CentER, Tilburg University, the Netherlands \\ Peter P. Wakker ${ }^{1}$ \\ Erasmus School of Economics, Erasmus University, Rotterdam, the Netherlands
}

August, 2010

\begin{abstract}
When process fairness deviates from outcome fairness, dynamic inconsistencies can arise as in nonexpected utility. Resolute choice (Machina) can restore dynamic consistency under nonexpected utility without using Strotz's precommitment. It can similarly justify dynamically consistent process fairness.
\end{abstract}

Key words: dynamic consistency, procedural fairness, time consistency, equity, nonexpected utility

JEL classification: D63, D81

\footnotetext{
${ }^{1}$ Corresponding author. Address: Erasmus University, Erasmus School of Economics, P.O. Box 1738, 3000 DR Rotterdam, the Netherlands; --31-(0)10 - 408.12 .65 (O), --31-(0)10 - 408.12.78/12.64 (S), --31-(0)10 - 408.91.62 (F); wakker@ese.eur.nl
} 


\section{Introduction}

Experimental studies have demonstrated the importance of fairness considerations in numerous strategic settings. Formal models have been developed for fairness preferences with many applications, e.g. in analyses of contracts. Two formal concepts are intentionbased reciprocity and outcome-based inequity aversion. Recently, process-based inequity aversion has been proposed, which does not require a role for intentionality. Then fairness of the outcome generating process matters rather than only the outcomes themselves, and inequity aversion is modeled using deviations from fair expected outcomes (Bolton et al. 2005, Krawczyk 2009, Trautmann 2009). Outcome fairness, in contrast, considers deviations from fairness regarding the actually obtained outcomes.

This paper shows that process fairness generates dilemmas of the same nature as nonexpected utility preferences do in dynamic decisions. These dilemmas are similar to Strotz' time inconsistency, but add a subtle role of counterfactual events. If process fairness is relevant, i.e. deviates from outcome fairness, then its implementation requires a violation of what is known as consequentialism (Machina 1989). Such violations will often be hard to implement. If they are not implemented, however, then dynamic inconsistency results. Thus under process fairness one of two natural conditions has to be abandoned, consequentialism or dynamic consistency. Process fairness and dynamic consistency can be implemented by commitment devices (Strotz 1955). For example, organizations typically serve as commitment device to implement process fairness in team production settings. Machina (1989) argued that even in the absence of commitment devices, dynamic consistency can be maintained by what McClennen (1990) called resolute choice.

\section{The Model}

Consider the following Random Ultimatum Game: For a pie, a random device proposes a share $\mathrm{x}$ for a responder, and a share $1-\mathrm{x}$ for a passive player $(\mathrm{x} \in[0,1])$. Assume that with equal probability the partition is $(\mathrm{y}, 1-\mathrm{y})$ or $(\mathrm{z}, 1-\mathrm{z})$. If the responder accepts, then both players receive their respective share. Otherwise (rejection) both players receive nothing. See Fig. 1. 


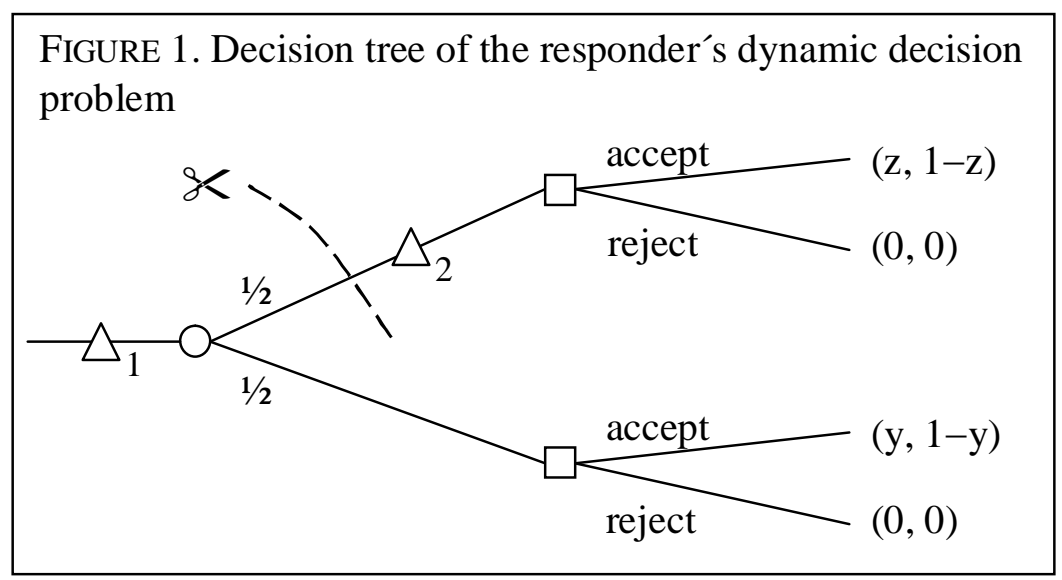

A circle (chance node) designates the random device's proposal of shares. Squares designate decision nodes where the proposer accepts or rejects. The outcomes are the final allocations $(\mathrm{x}, 1-\mathrm{x})(\mathrm{x}=\mathrm{y}$ or $\mathrm{x}=\mathrm{z})$ if acceptance, and $(0,0)$ if rejection. At either timepoint $\Delta_{1}$ (ex ante) or at timepoint $\Delta_{2}$ (ex post) the responder announces the decisions at all future decision nodes. If the responder announces ex ante (at $\Delta_{1}$ ), then she announces her decision for both decision nodes before the uncertainty is resolved. For the actual proposal resulting after the uncertainty has been resolved, her announced decision will then be implemented (she cannot reconsider). If the responder announces ex post (at $\left.\Delta_{2}\right)$, then the uncertainty has already been resolved in the past and the proposed allocation is $(\mathrm{z}, 1-\mathrm{z})$ (in the case depicted). She announces a decision that is immediately implemented.

Outcome fairness evaluations depend only on the realized outcomes $\mathrm{x}$ and $1-\mathrm{x}$. Fehr and Schmidt (1999) and Bolton and Ockenfels (2000) proposed models depending on deviations from equality $(\mathrm{x}=1 / 2)$, which reduce utility. Under process fairness evaluations, $\mathrm{x}$ and $1-x$ above are replaced by, or combined with, their expectations $E(x)$ and $E(1-x)$. Then the outcomes at both decision nodes matter.

\section{Process Fairness versus Separable Branches in the Decision Tree}

Outcome fairness is consequentialist (Machina 1989): Each branch of the decision tree is evaluated separately, as if the other counterfactual branches were non-existing. Both ex-ante $\left(\Delta_{1}\right)$ and ex-post $\left(\Delta_{2}\right)$ the decisions at the square nodes are evaluated in a forward looking 
manner. Past events and counterfactual parts of the tree are cut and play no more role, as illustrated in Fig. 1 for the evaluation of the upper branch. Each branch of the tree is evaluated de novo as McClennen (1990) called it. Ex ante outcome fairness can be related to Strotz' (1955) sophisticated choice: the consequentialist ex-post evaluations are anticipated ex-ante.

We will consider process fairness where the agent considers expected payoffs. Outcomes then are not evaluated separately from counterfactual outcomes in other branches of the tree. At both $\Delta_{1}$ and $\Delta_{2}$ the whole decision tree is taken into account. At each decision node, risks borne in the past are obviously relevant. Such relevance is the essence of Machina's (1989) resolute choice. Thus process fairness gives a convincing application of his idea, formalizing his Parental Example (Machina 1989, pp. 1643-1644). In Fig. 1 let $\mathrm{z}=0$ and $\mathrm{y}=1$. Then in $\Delta_{2}$ the responder facing the disadvantageous allocation $(0,1)$, unfair from an outcome perspective, accepts the offer because of her past chance of receiving $(1,0)$, which would have given her the whole pie. Good counterfactual outcomes impact on a bad outcome actually faced, making it acceptable.

\section{The Danger of Dynamic Inconsistency for Fairness Preferences}

Table 1 organizes possible combinations of decision time (ex post or ex ante) and decision perspective (process or outcome fairness). All four combinations are potentially conceivable. Dynamic consistency implies the same model before and after the resolution of uncertainty (either $\mathrm{P}_{1}$ and $\mathrm{P}_{2}$, or $\mathrm{O}_{1}$ and $\mathrm{O}_{2}$ ). Machina explicitly defended the rationality of dynamic consistency even in the absence of commitment devices, arguing that risks borne in the past continue to be relevant at present. This justifies ex-post procedural fairness; see the solid arrow in Table 1.

TABLE 1

Dynamic Consistency under Process and Outcome Fairness

\begin{tabular}{lcrl}
\hline & Ex-ante announcement $\Delta_{1}$ & Ex-post announcement $\Delta_{2}$ \\
\hline Process fairness & $\mathrm{P}_{1}$ & & $\mathrm{P}_{2}$ \\
Outcome fairness & $\mathrm{O}_{1}$ & $\mathrm{O}_{2}$ \\
\hline
\end{tabular}


The dashed arrow is empirically most plausible. In the ex-ante point $\Delta_{1}$ the whole decision tree is salient enhancing process fairness. Ex-post $\left(\Delta_{2}\right)$, however, the actually selected outcome allocation is most salient and counterfactual branches may be ignored. The latter consequentialist evaluation enhances outcome fairness ex post. Emotional factors support the dashed arrow (Bosman, Sutter, \& van Winden 2005; Loewenstein, 1996). It leads to violations of dynamic consistency of the same nature as commonly observed under nonexpected utility (Cubitt, Starmer, \& Sugden, 2004; Kahneman and Tversky 1979, isolation; Tversky and Kahneman 1986, pseudo-certainty; Volij, 1994) and similar to dynamic inconsistencies in intertemporal choice (Strotz, 1955; Thaler, 1981). Procrastination, undersaving, and unsuccessful dieting are some of the many resulting phenomena. Dynamic inconsistency is also central to macro-economics (Kydland \& Prescott 1977), where strategic considerations as in subgame perfectness play a role.

Every parent of two or more children can document anecdotal evidence on dynamic inconsistencies by a child who, after an a priori fair process, ends up with an ex post unfavorable outcome. Yet we are not aware of explicit reports of dynamic inconsistency in the fairness literature. There is clear evidence for the process view in ex-ante evaluations (Blount 1995; Bolton et al. 2005; Bolton and Ockenfels 2010). In ex-post evaluations, outcome fairness is more frequent although there is also some evidence for process fairness (Charness 2004; Cox and Deck 2005; Offerman 2002; van den Bos et al. 1997). These separate findings, if combined, suggest that dynamic inconsistencies will be common in fairness evaluations. No study as yet has, however, explicitly investigated such dynamic inconsistencies. Given the novelty of process fairness in the literature, this is an important topic for future research.

\section{Organizations as Devices to Promote the Process Fairness Perspective}

In the case of process and outcome fairness as for the dashed arrow in Table 1, organizations can serve as a commitment device to restore dynamic consistency. In team productions settings, outcomes are often indivisible (such as the allocation of attractive tasks). Then process fairness increases welfare by inducing inequity averse agents to participate. Organizations can promote the process view directly, so that agents will not reduce their utility for unequal outcomes. Alternatively, consider repeated settings where agents sometimes obtain more attractive projects and sometimes less attractive ones than their 
colleagues. Then contracts can guarantee participation even if agents obtain negative social utility from intermediate tasks, as long as the long term payoffs are positive. Studying the new models of process fairness in team production settings with dynamic inconsistency is a promising route to obtain insights into a new mechanism for the restoration of efficiency by firms where markets cannot provide such efficiency.

\section{Conclusion}

This paper has demonstrated that the implementation of process fairness and outcome fairness generates the same dilemmas as the implementation of nonexpected utility in dynamic decisions. These dilemmas are similar to Strotz' time inconsistency. Machina's (1989) resolute choice can justify process fairness even if no commitment device is available. Conversely, process fairness can serve to provide psychological background for Machina's resolute choice.

\section{References}

Blount, S. (1995). When social outcomes aren't fair: the effect of causal attributions on preferences. Organizational Behavior and Human Decision Processes, 63, 131-144.

Bolton, G. E., Brandts, J. \& Ockenfels, A. (2005). Fair procedures: evidence from games involving lotteries. Economic Journal, 115, 1054-1076.

Bolton, G. E. \& Ockenfels, A. (2000). ERC: A theory of equity, reciprocity, and competition. American Economic Review, 90, 166-193.

Bolton, G. E. \& Ockenfels, A. (2010). Betrayal Aversion: Evidence from Brazil, China, Oman, Switzerland, Turkey, and the United States: Comment. American Economic Review 100, 628-633.

Bosman, R., Sutter, M. \& van Winden, F. (2005). The impact of real effort and emotions in the power-to-take game. Journal of Economic Psychology, 26, 407-429.

Charness, G. (2004). Attribution and Reciprocity in an Experimental Labor Market. Journal of Labor Economics, 22, 665-688.

Cox, J. C. \& Deck, C. A. (2005). On the nature of reciprocal motives. Economic Inquiry, 43, $623-635$. 
Cubitt, R. P., Starmer, C., \& Sugden, R. (2004). Dynamic Decisions under Uncertainty: Some Recent Evidence from Economics and Psychology. In I. Brocas \& J. D. Carrillo (Eds.), The Psychology of Economic Decisions (Vol. II): Reasons and Choices, Oxford University Press: New York, 81-107.

Fehr, E. \& Schmidt, K. (1999). A Theory of Fairness, Competition and Cooperation. Quarterly Journal of Economics, 114, 817-868.

Kahneman, D. \& Tversky, A. (1979). Prospect Theory: An Analysis of Decision under Risk. Econometrica, 47, 263-291.

Krawczyk, M. W. (2009). A model of procedural and distributive fairness. Theory and Decision, forthcoming.

Kydland, F.E. \& Prescott, E.C. (1977). Rules rather than Discretion: The Inconsistency of Optimal Plans. Journal of Political Economy, 85, 473-491.

Loewenstein, G. (1996). Out of control: Visceral influences on behavior. Organizational Behavior and Human Decision Processes, 65, 272-292.

Machina, M.J. (1989). Dynamic consistency and non-expected utility models of choice under uncertainty. Journal of Economic Literature, 27, 1622-1668.

McClennen, E.F. (1990). Rationality and Dynamic Choice: Foundational Explorations. Cambridge University Press, Cambridge, UK.

Offerman, T. (2002). Hurting Hurts More Than Helping Helps. European Economic Review, $46,1423-1437$.

Strotz, R.H. (1955). Myopia and inconsistency in dynamic utility maximization. Review of Economic Studies, 23, 165-180.

Thaler, R. (1981). Some Empirical Evidence on Dynamic Consistency. Economics Letters, 8, 201-207.

Trautmann, S. T. (2009). A Tractable model of process fairness under risk. Journal of Economic Psychology, 30, 803-813.

Tversky, A. \& Kahneman, D. (1986). Rational Choice and the Framing of Decisions. Journal of Business, 59, S251-S278.

Van den Bos, K., Vermunt, R., \& Wilke, H.A.M. (1997). Procedural and Distributive Justice: What is Fair Depends More on What comes First Than on What Comes Next. Journal of Personality and Social Psychology, 72, 95-104. 
Volij, O. (1994). Dynamic consistency, consequentialism and reduction of compound Lotteries. Economics Letters, 46, 121-129. 